\title{
EVOKING MOTIVATION For ACHIEVEMENT IN Ó’ LEVEL MATHEMATICS IN ZiMBABWE
}

\author{
Chipo Makamure \\ Belvedere Technical Teachers College, Zimbabwe
}

\begin{abstract}
With reference to continuous poor quality performance in mathematics in Zimbabwe, this study attempts to answer recurring questions about how to get more students interested and involved in mathematics at ' $O$ ' level in Zimbabwe. The motivational factors previously discussed are often perceived as invariable. These factors may diminish, intensify or new ones may develop, especially with the advent of modern technology for teaching. A qualitative design was used to collect and analyse data from the students and teachers through focus group interviews and observation respectively. The study found that external forces can influence students' motivation to learn mathematics but ultimately, it is the internal forces that sustain the motivation. Course structures, teaching methods and teacher attitude were found to be contributory factors to students' motivation in mathematics. The study recommends that mathematics teachers apply more personalised and process-oriented approaches to teaching, to empower learners. The study also recommends institutional changes that encourage pedagogical modifications to stimulate student interest and learning outcomes in mathematics.
\end{abstract}

\section{KEYWORDS}

Motivation, Achievement, Mathematics Education, Teaching Strategies, Interest

\section{INTRODUCTION AND BACKGROUND}

The purpose of this study is to discuss motivational strategies and how the se strategies mediate or inhibit achievement in mathematics among "O" Level mathematics students in Zimbabwe. A lot of work has been done on motivation outside the domain of mathematics (Middleton and Spanias, 1999). Hence, this study focusses on motivation that involves the teaching and learning of mathematics at "O" level.

The value of mathematics in Zimbabwe and the world over cannot be over-emphasised. More importantly, mathematics has been considered indispensable because of its continued and ever increasing services to other areas of study, in industry and in everyday life (Meshack, 2013). The value accorded to mathematics has made underachievement in mathematics a pertinent issue. In Zimbabwe, mathematics appears conspicuously in the curriculum of primary and secondary schools. Every student who passes through these institutions of learning is supposed to learn the subject compulsorily.

Despite the importance that is attached to mathematics as a subject, mathematics in general appears to be unpopular as a high school subject (Middleton and Spanias, 1999). Student achievement in mathematics has remained low across the world. According to Meshack (2013), many actions have been implemented to set a stage for better performance in mathematics but have failed to address performance deficits in secondary school mathematics. In Zimbabwe, no matter how crucial mathematics is, there has been a growing national concern about the level of student achievement over the past several years (Basira, 2012, ZIMSEC Result analysis, 2015). 
Problems of mathematics underperformance are still unabated and the solution to mathematics underachievement in Zimbabwe remains elusive. In search of possible solutions to this challenge of poor performance in mathematics, this study explored the possible strategies to evoke motivation for achievement in 'O' level mathematics in Zimbabwe. Dickson (2018) asserts that the absence of motivation has significantly contributed to poor performance of students. In the same vein, Sartawi et al (2012) reveals that a factor of "academic motivation" is clearly related to mathematics achievement. Hence, motivation and academic achievement in mathematics are perceived as developmentally interlocked (Garon-Carrier, 2016). In their study, Middleton and Spanias (1999) found that motivation cannot just develop naturally in a learner, but can be formed, modified and sustained. For this reason, there is need for a better understanding of the factors that are likely to impact on the students' motivation and evoke interest to learn mathematics at ' $\mathrm{O}$ ' level in Zimbabwe. The study therefore seeks to answer the following research questions: What factors influence the development of motivation to learn ' $O$ ' level mathematics in Zimbabwe? What measures can be put in place to enhance and sustain motivation and achievement in mathematics in Zimbabwe?

\section{Statement Of The Problem}

Despite the many studies that have been carried out and recommendations given and implemented, the problem of underachievement in mathematics has remained unsatisfactory and unabated (Meshack, 2013). This problem is attributed to lack of interest to learn mathematics (Garon-Carrier, 2016). Issues on motivation in relation to mathematics have not been exhaustively studied. The study thus delves into the strategies of evoking motivation to learn mathematics at ' $\mathrm{O}$ ' level in Zimbabwe

\section{THEORETICAL FrameWORK AND REVIEW Of RELATEd Literature}

The study is informed by the self-determination theory (SDT) introduced by Ryan and Deci (2000). The theory provides a perspective of intrinsic and extrinsic motivation. These two types of motivation are viewed by the SDT in the same context and not as opposing entities (Takahashi, 2018). According to the SDT, learners are said to be motivated if engagement in an activity is heavily dependent on a self-determined factor. A simple definition of motivation was given by Hannula (2006) as the "tendency to do something and avoid doing some others". This implies that motivation is the desire or the push to do some activity. Meshack (2013) avows that motivation has much to do with ambition and if the ambition is absent, then motivation is absent too. In the context of this study, motivation is what propels learners to engage in mathematical activities in and outside the classroom. Intrinsic motivation is when behaviour is exhibited willingly without an internal or external influence (Sartawi et al, 2012). This definition suggests that learners are engaged in the learning activities because they enjoy them. Extrinsically motivated learners are engaged in mathematical activities because they look forward to receiving desirable outcomes, for example, acclaims from teachers and parents.

Takahashi (2018) noted the four categories of motivation namely, amotivation, external regulation, introjected regulation, identified regulation and the integrated regulation. According to the SDT, the four categories are all forms of extrinsic motivation. However, since there are variations among the categories in terms of the degree of levels of autonomy, integrated regulation is more internalised than the external regulation (Ryan \& Deci, 2000). Hence, internalised motivation is considered intrinsic motivation in which learning is due to internal drive rather than a means for achieving goals (Takahashi, 2018). SDT is based on the view that intrinsic motivation is contextual and can change to extrinsic motivation. Based on this theory, both academic and level of motivation of students are dependent upon an individual's feelings of autonomy. The SDT can be reinforced by Keller's ARCS model of motivational design. Keller's 
(1995) model of motivational design views motivation as a sequence of events that may include Attention, Relevance, Confidence and Satisfaction (ARCS model). For example, Keller asserts that teachers first gain the attention of the learners and then provide relevance of what they are teaching to the learners' personal goals and needs. The learners will then gain confidence as the learning process unfolds. The satisfaction of the new knowledge then provides motivation to continue learning. The study hence focuses on the factors that ensure satisfaction as the ultimate result of the learning process among mathematics students at ' $O$ ' level in Zimbabwe.

\subsection{Components of Motivation}

Frith (1997) identified components of the motivation to learn, some being: curiosity, selfefficacy, competence and reinforcement. Frith avers that people are naturally curious and thus, they seek new experiences, they enjoy learning new things, they find satisfaction in solving puzzles, perfecting skills and developing competence. This implies that a major task in teaching is to nurture students' curiosity and use curiosity as a motive for learning. Self-efficacy can be the feeling that what one is doing is worth the effort. High self-efficacy is therefore important in the development of motivation to learn mathematics because it signifies engagement and positive regard for the school work. To promote competence, Frith (1997) asserts that teachers need not provide situations where success only will take place. Tasks given to students in the classroom should therefore be challenging but achievable (Middleton and Spanias, 1999). The achievement of competence may then become a motivating factor. Reinforcement is a form of external motivator (Frith, 1997). Through reinforcement, students gain confidence when they are praised or encouraged. Sometimes such praises must be accepted because students must feel that their views and perspectives are being valued. Hence, Dickson (2018) contends that a fearful mind blocks the learning and understanding capacity of students and as a result, performance of students decelerates. To support the ideas above, Pantziara \& Philippou (2015) designed a model for students' motivation in a mathematics classroom.

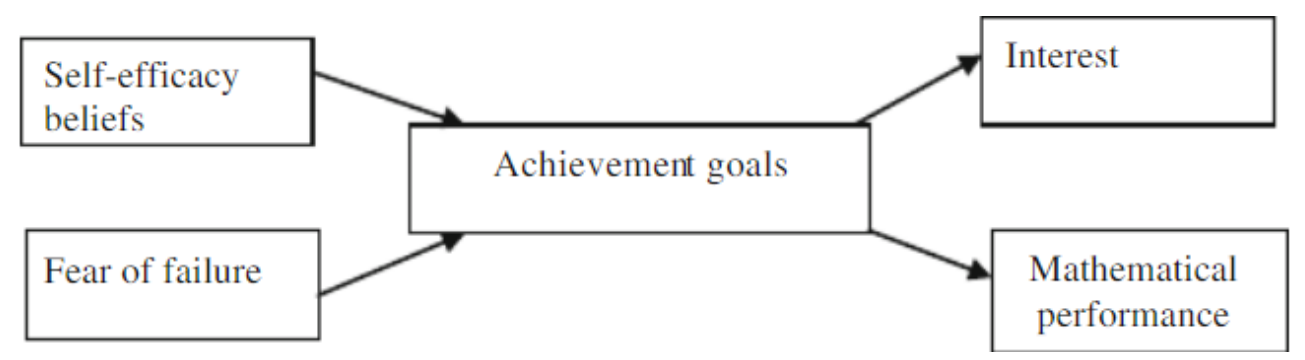

Figure 1: A model of students' motivational constructs and outcomes by Pantziara \& Philippou (2015)

The model shows that self-efficacy influences mastery goals and fear of failure influences performance goals and performance avoidance. However, Mastery goals (achievement goals) have a direct effect on leaners' mathematical performance and interest. This shows that selfefficacy, competence and motivation are intertwined.

\section{Methodology}

\subsection{Research Design and Data Collection Procedures}

A constructivist view was used to select the qualitative design to collect and analyse data. Focus group interviews were held with 30 ' $\mathrm{O}$ ' level mathematics students (15 to 16 years of age, 5 per group) from 6 schools in and around Harare, to unravel the learners' perspectives about studying mathematics. Five teachers were interviewed to establish their views about learners' attitude, aptitude and/or interest in learning mathematics. The interviews also sought to establish the 
teachers' strategies of and perspectives towards teaching mathematics. The same teachers who were interviewed were also observed twice each to find out how they shared lessons with the learners. Data collected from the learners were audio recorded. Field notes were also written to complement the recorded data. An observation schedule was prepared to establish students' engagement, students' performance, strategies of teaching and how captivating they were and persistence of learners in the face of a challenge as indicators of motivation. Responses from interviews with teachers and students were compared with the classroom observation results.

\subsection{Data Analysis procedures}

Data from the interviews were categorised into related themes, explained and analysed. Pseudonyms were used in the interviews for ethical reasons.

\section{RESUlts AND DisCUSSION OF FINDINGS}

\subsection{Practical vs Rote Learning:}

All the teachers who were interviewed in this study used more of teacher-centred approaches of teaching than student-centred approaches. Teaching was more of drill and practice, demonstration, lecture/telling and textbook driven. In addition, more than $70 \%$ of the learners, after being asked during focus group interviews how they are taught mathematics by their teachers and how they feel about the subject, expressed fear and lack of confidence in the subject. For example, one student, Rosemary avers;

Aah, the teachers tell us how the problems are solved. I used to like mathematics but every time we are given an exercise, I fail to understand the questions, no matter how hard I try. I have lost all the hope of passing it and I don't think I can pass the exam. It is only that mathematics is compulsory, I should have dropped it....

John, a student in a different focus group added, " I like mathematics but sometimes the teacher assumes we all understand what he is teaching. He will be rushing, and as a result, I have problems with mathematics..."

The above speeches raised two issues, namely, attainment and teaching methods as being instrumental in motivation development in mathematics. First, Rosemary and John show that they are struggling with mathematics. Their challenges in the subject are then compelling them to give up on mathematics. This suggests that achievement in mathematics predicts motivation (GaronCarrier, 2016) and is self-reinforcing. Meshack (2013) also asserts that learners normally have no drive to learn and persevere with tasks if they believe that their actions will not bear desirable outcomes. In addition, Middleton (1999) asserts that students normally engage in mathematics if they expect to pass, otherwise they remain disoriented and tend to avoid the subject. Secondly, from Rosemary's speech, it is likely that the teacher's strategy of "telling" the students may affect the learners' desire and understanding of mathematics. This is concurred by the results of both the teacher interviews and the observation in the study. Most teachers who were interviewed showed that they adhered to traditional ways of teaching. The methods were repetitive and monotonous. One teacher, Emmilia, was observed teaching Pythagoras' theorem to the form $3 \mathrm{~s}$. Students were provided with a formula to memorise $\mathbf{a}^{2}+\mathbf{b}^{2}=\mathbf{c}^{2}$ and solve tasks. The teacher proceeded to work out an example on the board and asked the students to follow suit. It could be more interesting if students were engaged in the classroom activities/puzzles where the students could experiment with different squares, joining any two squares of different sizes at right angles. The third square is then formed by joining the other two to form a right-angled triangle in the middle. 
The students may be able to establish the relationship between the 3 squares as $\mathbf{a}^{2}+\mathbf{b}^{2}=\mathbf{c}^{2}$. That is, the biggest square has the exact same area as the other two squares put together (Figure 2 ). The students should initially focus more on the squares rather than the triangle. Driscoll (2015) thus, posits that mathematics is effectively learned solely by experimenting, questioning, reflecting, and discussing. According to Keller's ARCS model of teaching, the

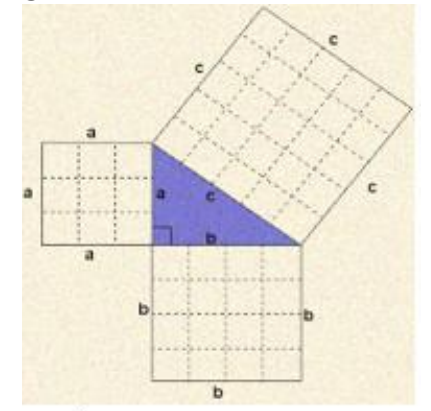

Figure 2

attention of the learners can be drawn when they become more engaged and when learning is active, interactive and challenging. Hein (2012) thus, considers the teachers' approach to a topic as the key factor in determining the level of motivation in students. Teachers, therefore, should be very meticulous in the way they deliver information to the learners to maintain the desire to learn mathematics.

\subsection{Teacher Perception of Mathematics teaching, Learning and Learners}

When asked to explain the leaners' performance, attitude and interest in mathematics and how teachers teach mathematics, three teachers indicated that students had a prevailing form of negative thinking and/or feeling of the subject. For instance, Phillip, one of the teachers interviewed said; "Generally the students I teach are slow learners, they are hopeless and because of that, I have absolutely no hope of them passing mathematics." However, after being asked how he intended to remedy this problem, the teacher seemed to have no solution to the problem. Analysing both the students and the teacher's speeches reveals that both the teacher and the students need assistance. Whilst the students need to be rescued from the situation of motivation erosion, the teacher's attitude towards slow learners is quite disheartening. The problems arising from the teacher can be well explained as follows:

The teacher believes in aptitude or ability as a major contributory factor to underachievement in mathematics. As a result, the teacher does not apply effort to rescue the learners who are already drenched in a pool of confusion as far as learning mathematics is concerned. He believes that success in mathematics for such learners is unattainable. The beleaguered students' effort to learn mathematics can be exhausted and the teachers' effort to assist the students thus, becomes derelict. Ultimately, the students lose interest in mathematics because they think it is unachievable. It has been noted by Middleton and Spanias (1999) that most educational environments have placed high value on ability as a contributory factor to achievement in mathematics than effort. It is therefore prudent that teachers know the learners, their difficulties and abilities to assist them accordingly.

\subsection{Book Driven Approaches VS Experiential learning}

Both the observation and teacher interviews in this study revealed that most lessons were text book driven. All the teachers in the study strictly followed the text book, to solve the problems. This observation was concurred by a teacher, Mary, who was interviewed and explained how she taught the topic "angles between planes" to form four students. From her explanation, students 
were likely to memorise the concepts without understanding or being able to visualise the actual object they are being introduced to. The teacher strictly followed the example given in the text book (Figure 3a) to explain the concept of "angles and planes", to which she agreed that students had challenges understanding the topic. More so, the topic was unpopular to the students, she reported. Mosvold (2005), stressed that students should be assisted to see how skills learnt in the classroom are applicable in the real world so that motivation could be promoted. Hence, learning can be enriched, brought to life and motivation and participation in the classroom can be improved if teachers demonstrate the practical uses of mathematics. For example, the topic referred to above "Angles between planes" may be more captivating to the learner if the teacher engages them in the real-life experiences, by demonstrating angles and planes on the houses that the learners stay in, on a daily basis, as follows:

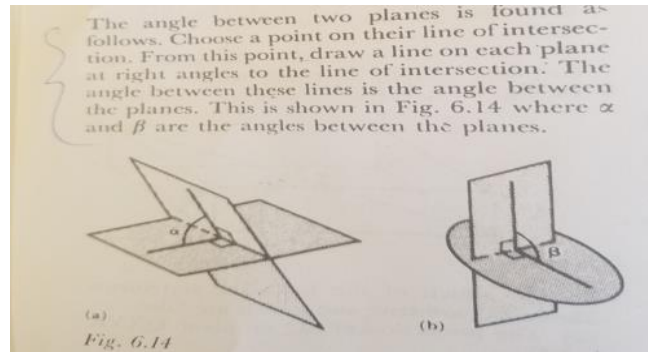

Figure 3: New General Mathematics book 4

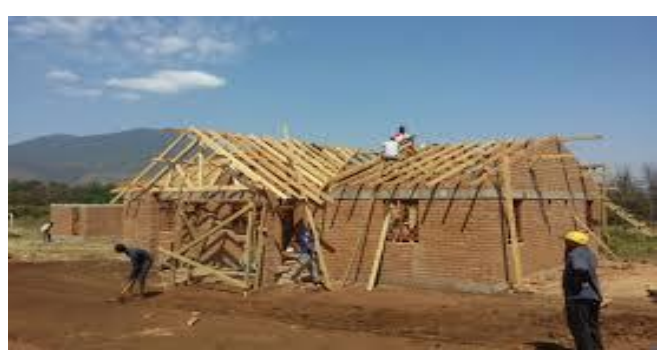

VS practical experience (Concept of relevance)

It may be fascinating when students realise that they live with mathematics and live in mathematics. There is a concept of relevance and the subject ceases to be alien/strange. This way, the students are likely to have the drive to learn and understand mathematics better. According to Keller (1987) relevance in a learning activity can be developed when instruction in the classroom is related to concrete examples within the learners' experiences. Once the student sees the relevance, she may be able to set goals. Self-imposed goals provide confidence and satisfaction for the learner and this can be a significant source of motivation (Keller, 1987).

\subsection{Interplay Between Vicarious Experience and Motivation}

The study also revealed that vicarious learning plays a crucial role in determining student motivation to learn mathematics. When asked about her perception towards mathematics and why she was taking mathematics, Grace, a student, expressed her views (laughing) as follows;

"Ummm, ... because it is compulsory. The truth is, I am not talented in mathematics. No one passed it in my family." Grace's desire to learn mathematics was drowned by the failure of her siblings in mathematics. She is attributing her failure and phobia in mathematics to heredity, talent and ability. Hence, Meshack (2013) contends that mathematics learners who doubt their abilities are likely to avoid the subject, hence experiencing detrimental factors such as stress and depression. Fried (2011) contends that when a learner is stressed, the major part of the brain shuts down and reverts to survival needs such as defensiveness and attention seeking. This stress may become a motivation barrier in the classroom. This view is complemented by the student Jack, in the same focus group, who expressed his desire to pursue mathematics because everybody in the family, including the parents passed mathematics. It is this social background that pushed Jack to remain resilient and persistent on mathematical activities. It may therefore be prudent that teachers exhibit positive attitude and interest towards mathematics that can be emulated by the students so that the learners may also pursue the subject with interest. 


\subsection{Indigenous Learning to Enhance Motivation}

Two teachers were observed teaching algebraic expressions and probability respectively during the study. It was found that in their assessment criteria, the teachers picked any examples regardless of whether the learners were conversant with them or not. For example, Austin, one of the teachers was observed teaching probability using playing cards at a rural school outside Harare. Some students were struggling to understand the structure of the playing cards instead of focusing on the questions to be answered. It was hard for them to answer a question without knowing, for example, the number of shrubs in the set. A thorough analysis of the lessons showed that sometimes teachers need to understand the social background of the class and the social community in which they are teaching before lesson presentation, so that they are able to teach for understanding and motivate the learners. Word problems involving playing cards for students who are not familiar with such games may be meaningless. Such problems could hide the conceptual foundation of 'probability' for these students and are liable to hindering their understanding of the topic (Makamure 2016). Keller (1987) contends that if the subject content has no perceived value to the learners, their motivation is automatically lost. If familiar terms or local games such as tsoro (the Zimbabwean traditional game that is played by digging rows and columns of small holes in the ground which are then filled with a pre-determined amount of stones or seeds.) are used in the examples therefore, it can interest the learners and they may be able to understand and see the relevance of learning probability, hence motivation is enhanced.

\subsection{Computer Technology}

When asked the level of use of ICT during lessons, teachers, by and large, had concerns that included lack of facilities, lack of the appropriate software and incompetence to use computers. The challenges alluded to, portray the fact that training, probably in form of workshops and seminars is necessary to equip teachers with the computer expertise. With more integration of ICT in the teaching and learning of mathematics, students' attention may be attracted, hence provoking interest to learn mathematics. Dockendorff \& Solar (2017), thus, assert that teachers can increase their students' interest in mathematics by incorporating the use of technology to facilitate learning and teaching. According to Frith (2011) human beings are naturally curious, hence, they seek new experiences and they enjoy learning new things. This implies that students' curiosity can be nurtured as a motive for learning mathematics through the use of new technology.

\subsection{Other External Motivators}

The interviews with the students revealed that, among other factors, they are propelled to study mathematics because of the desire to get a good job after school, the support and encouragement from teachers and parents and for prestige since mathematics is considered a peculiar subject. The students' responses show that extrinsic motivation has a role to play in the development of mathematics interest and proficiency. Hence, Sartawi et al (2012) assert that students do well in mathematics when they get acclaims and support from outsiders such as parents and teachers.

After being asked to explain why mathematics pass rates are low in the country, 4 out of 5 teachers mentioned poor salary structures, over-crowded classes that they could not attend to the students individually, especially where the students needed special attention. They also raised the issue of basic facilities lacking in the schools, leading to job dissatisfaction. Due to this, teachers are abandoning their duties for other businesses, leaving the students to their fate. 
Thomas, one of the teachers who was interviewed concurred: "The working conditions are just unbearable. ..... students have no books, they have no access to internet, the classes are too large, the furniture is inadequate and salaries are low. "

The sentiments by Thomas are in line with the "social exchange theory" of Leithwood (2006) which postulates that when employees are committed and dedicated, they need to be rewarded by the employer. Thus, a happy teacher develops an interested learner. This suggests that the interest and quality of teaching mathematics is likely to be influenced by the degree to which the teachers' desires are satisfied (Makamure, 2016).

\section{CONCLUSION AND RECOMMENDATIONS}

The study revealed that teachers have sold mathematics short by the way they present the subject to the learners. Student motivation to learn mathematics therefore may improve when teachers begin to construct a mathematics curriculum that focuses on creating meaning in solving mathematical problems rather than memorising facts. Mathematics motivation or phobia is therefore, not an inherited tendency but can be created. Based on these findings, this study therefore, recommends that mathematics teachers apply more personalised and process-oriented approaches to teaching, to empower learners. The study also recommends institutional changes that encourage pedagogical modifications to stimulate student interest and learning outcomes in mathematics. Learning should give the students the opportunity to work autonomously, to invent and discover knowledge through project and inquiry-based approaches so that learning becomes relevant and authentic to enhance motivation. Lastly, teachers should be incentivised accordingly to improve performance

\section{REFERENCES}

[1] Dickson, O. (2018). Effects of extrinsic motivation on secondary school students' academic achievement in social studies. International Journal of Education (IJE), 6(3), 1-7. DOI : 10.5121/ije.2018.6301

[2] Dockendorff, M., \& Solar, H. (2018). ICT Integration in Mathematics Initial Teacher Training and Its Impact on Visualisation: The case of GeoGebra. International Journal of Mathematical Education in Science and Technology, 49(1), 1-6.

[3] Frith, C. (1997). Motivation to Learn. Educational Communications and Technology. University of Saskatchewan.

[4] Garon-Carrier, G. (2016). Intrinsic Motivation and Achievement in Mathematics in Elementary School: A Longitudinal Investigation of Their Association. Retrieved From https://corpus.ulaval.ca

[5] Hannula, M. (2006). Motivation in Mathematics: Goals Reflected in Emotions. Educational Studies in Mathematics, 63(2), 165-178.

[6] Hein, V. (2012). The Effect of Teacher Behaviour on Students Motivation and Learning Outcomes: A Review. Acta Kinesiologiae Universitatis Tartuensis, 18, 9-19.

[7] Keller, J.M. (1987). Development and Use of the ARCS Model of Motivational Design. Journal of Instructional Development, 10(3), 2-10.

[8] Leithwood, K. (2006). Teacher working conditions that matter: Evidence for change. Toronto: Elementary Teachers' Federation of Ontario. 
[9] Makamure, C. (2016). Learning to Teach Secondary School Mathematics From Practice: An Exploration of the Zimbabwean Pre-service Teachers' Year-Long Field Experiences. University of the Free State. South Africa.

[10] Meshack, E.O. (2013). The Role of School and Motivational Factors in Mathematics Achievement and Self-Efficacy: A Multi-Level Analysis. ETD Archive. Paper 203.

[11] Middleton, J.A., \& Spanias, P.A. (1999). Motivation for Achievement in Mathematics: Findings, Generalisations and Criticisms of the Research. Journal for Research in mathematics Education, 30(1), 65-88.

[12] Mosvold, R. (2005). Mathematics in Everyday Life: A Study of Beliefs and Actions. Department of Mathematics, University of Bergen.

[13] Pantziara, M., \& Phillipou, G. (2015). Students' Motivation in the Classroom: Revealing Causes and Consequences. International Journal of Science and Mathematics Education, 13(2), 385-411.

[14] Ryan, M.R., \& Deci, L.E. (2000b). Self-Determinant Theory and the Facilitation of Intrinsic Motivation, Social Development and Well-being. American Psychologist, 55, 68-78

[15] Sartawi, A.; Alsawaie, O.N.; Dodeen, H.; Tibis, S.; \& Alghazo, I.M. (2012). Predicting Mathematics Achievement by Motivation and Self-Efficacy Across Gender and Achievement Levels. Interdisciplinary Journal of Teaching and learning, 2(2).

[16] Takahashi, T. (2018). Motivation of Students for Learning English in Rwandan Schools. Issues in Educational Research, 28(1), 168-186.

[17] Vero, E. (2017). The Importance of Motivation in an Educational Environment. European University of Tirana. https://doi: 107346/-fei-XV. -01-1. 7._05

\section{Author}

Dr Chipo Makamure is a Mathematics lecturer in the Department of Natural Sciences at Belvedere Technical Teachers' College, Number 1 Harvard road, Belvedere, Harare, Zimbabwe. She holds a Phd in Curriculum Studies from the Free State University, South Africa. Her research interests include Teacher Development in Mathematics.

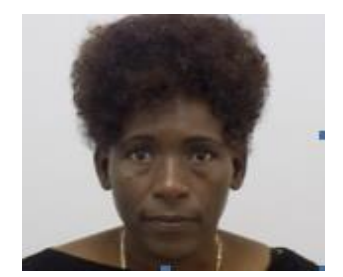

